\title{
Assessment of population substructure in relation to summer feeding ground use in the eastern North Pacific gray whale
}

\author{
Timothy R. Frasier ${ }^{1,3, *}$, Sharlene M. Koroscil ${ }^{1}$, Bradley N. White ${ }^{1}$, James D. Darling ${ }^{2}$ \\ ${ }^{1}$ Natural Resources DNA Profiling and Forensic Centre, Department of Biology, Trent University, \\ Peterborough, Ontario, K9J 7B8, Canada \\ ${ }^{2}$ Pacific Wildlife Foundation, Vancouver, British Columbia, V3H 1V6, Canada \\ ${ }^{3}$ Present address: Department of Biology, Saint Mary's University, Halifax, Nova Scotia, B3H 3C3, Canada
}

\begin{abstract}
The eastern North Pacific gray whale Eschrichtius robustus was removed from the US Endangered Species List in 1994, and since then aboriginal groups in Washington (USA) and British Columbia (Canada) have discussed the resumption of traditional whaling. In particular, the Makah are pursuing legal permission to resume their hunt. Although the majority of whales in this population migrate to summer feeding grounds in the Bering, Chukchi, and Beaufort Seas, a small number of individuals $(200)$ spend the summers feeding in the waters ranging from northern California to southeast Alaska. The relationship of these 'southern feeding group' whales to the rest of the population is unknown. This information is key to making appropriate management decisions, because these whales inhabit the waters directly adjacent to the aboriginal communities interested in resuming whaling. We compared mitochondrial sequence data from 40 southern feeding group individuals to sequences from 105 individuals representing the larger population. We found significant differences in haplotype frequencies between the 2 groups, with an estimated long-term rate of exchange between the groups being $<<1 \%$. Moreover, estimates of $\Theta\left(N_{\mathrm{e}} \mu\right.$ for mtDNA data, i.e. the probability of a mutation occurring within the population in each generation) were significantly different between the 2 groups, indicating that the maternal lineages of the southern feeding group represent a distinct seasonal subpopulation. Combined, these data show that the southern feeding group of gray whales qualifies as a separate management unit, which should be considered when making conservation decisions.
\end{abstract}

KEY WORDS: Gray whale · Eschrichtius robustus - Whaling • Population structure · mtDNA • Management unit

Resale or republication not permitted without written consent of the publisher

\section{INTRODUCTION}

The eastern North Pacific gray whale Eschrichtius robustus represents one of the few populations that have been removed from the US Endangered Species List, with the classification changing from 'endangered' to 'recovered' in 1994. Commercial whaling targeting gray whales in the eastern Pacific began in 1845 (Henderson 1984) and reduced the population from an estimated 12000-15000 ind. to as low as
1500-1900 ind. by 1900 (Henderson 1984, Reilly 1992, Butterworth et al. 2002). International protection began in 1937, when the United States and Norway ended their gray whale hunts, but it was not until 1951 that all modern whaling countries agreed to stop hunting gray whales (Reeves 1984). Systematic surveys from 1967 to 1998 showed that the population increased at an annual rate of $\sim 2.6 \%$, reaching as many as 30000 ind. (Shelden \& Laake 2002, Rugh et al. 2005). Current estimates hover around 20000 ind., and 
there are even some suggestions that the population has reached carrying capacity (Moore et al. 2001, Wade 2002, Rugh et al. 2005, but see Alter et al. 2007 for an alternative perspective).

During the late fall and early winter, whales migrate to the lagoons of Baja California and the Gulf of California, which represent the winter calving grounds for this population (Swartz 1986, Findley \& Vidal 2002, Swartz et al. 2006). During the spring, the majority of whales migrate to their northern feeding grounds in the Bering, Chukchi, and Beaufort Seas (Moore \& Ljungblad 1984). However, a small subset of the population ( 200 ind.) remains in more southerly feeding grounds ranging from northern California to southeast Alaska (Pike 1962, Hatler \& Darling 1974, Darling 1984, Darling et al. 1998, Calambokidis et al. 2002, Swartz et al. 2006). These 2 subsets of the population will be referred to as the southern feeding group and the larger population, respectively.

Subdivision with respect to summer feeding ground use is common in baleen whales, and results from maternally directed site fidelity to different feeding grounds. For example, in humpback whales Megaptera novaeangliae and North Atlantic right whales Eubalaena glacialis, calves nurse for 11 mo (and occasionally longer) and learn migration routes and the location of summer feeding grounds through cultural transmission from their mother (e.g. Baker et al. 1990, Malik et al. 1999). Thus, if there is differential use of feeding grounds by mothers, these preferences will be passed on to their offspring and result in substructuring with respect to summer feeding ground use. Gray whale calves nurse for a much shorter period of time ( 6 mo; Swartz 1986). Although their length of lactation is still long enough to learn migratory routes and the location of summer feeding grounds, it is not yet clear whether gray whales show this maternally directed site fidelity. Because mitochondrial DNA (mtDNA) is maternally inherited, patterns of mtDNA diversity should reflect any maternally based patterns of movement and distribution. Therefore, analysis of mtDNA is ideal for testing hypotheses of maternally based site fidelity and subsequent population structure in baleen whales.

The relationship between the southern feeding group and the larger population is unknown. It is currently assumed that both of these groups use the same breeding ground, and therefore represent the same breeding population (e.g. Swartz et al. 2006). Given the known patterns in other baleen whale species, it seems likely that the southern feeding group and the larger population, and perhaps even smaller, as yet undefined subdivisions, result from maternally directed site fidelity to different feeding grounds by gray whale mothers. Photo-identification data are con- sistent with this hypothesis, showing that the majority of whales sighted in the southern feeding areas are resighted there in subsequent years, and therefore show the expected site fidelity (Darling 1984, Calambokidis et al. 2002, 2010). For example, Calambokidis et al. (2002) found that between 70 and $100 \%$ of the whales photo-identified off British Columbia had been sighted there in previous years. Moreover, the majority (63\%) of calves first sighted in the southern feeding area with their mothers are resighted there in subsequent years, suggesting that this differential use of feeding grounds is indeed the result of maternally directed site fidelity (Calambokidis et al. 2010). This resighting rate is high, given the numerous factors that can reduce the resighting rates of calves, including: (1) mortality of individuals between their calf and subsequent year (as this age class has the highest mortality rate in many mammalian populations; Caughley 1966); and (2) changes in physical features that prevent re-identification (Calambokidis et al. 2010). However, preliminary genetic analyses of population structure based on mtDNA were inconclusive (Steeves et al. 2001).

Understanding the relationship between the southern feeding group and the rest of the population is of increasing importance due to the intention of some aboriginal communities to resume hunting gray whales. Several aboriginal groups traditionally hunted gray whales, but voluntarily stopped hunting as whale numbers decreased and/or were required to stop when the population received international protection (O'Leary 1984, Russell 2004). The exception was off Chukotka, Russia, where whaling was allowed to continue. In 1998, the Makah (in Washington, USA) resumed whaling and caught/killed a whale in 1999, but have been prevented from continuing since 2000 by litigation. Specifically, the Makah were given the right to hunt gray whales at traditional sites under the Treaty of Neah Bay in 1855. However, a final court ruling in 2004 determined that in order to resume their hunt, they must follow the necessary procedures for obtaining a waiver under the Marine Mammal Protection Act (MMPA). The Makah have applied for this waiver, and this request is still being processed. The outcome of the Makah application will have large implications for the resumption of whaling by other aboriginal communities in the area as well (Russell 2004).

The relationship of these 'southern feeding group' whales to the rest of the population is unknown. This information is key to making appropriate management decisions, because these whales inhabit the waters directly adjacent to the aboriginal communities interested in resuming whaling. The negative consequences of ignoring potential population structure when making management decisions, such as the extinction of unrecognized populations and/or species, 
are well known (e.g. Daugherty et al. 1990, Taylor 1997, Frankham et al. 2002). For the current gray whale situation, an understanding of population substructure in relation to known summer feeding ground use is required to infer how the whales in each feeding area, and the population as a whole, will respond to the removal of individuals through the proposed hunts. Therefore, if informed management decisions are to be made regarding resuming this hunt, it is first necessary to understand the relationship of this southern feeding group to the rest of the larger population. Here, we conducted analyses of the mitochondrial DNA of gray whales representing the southern feeding group, as well as the larger population, in order to better understand their relationship, and therefore inform management decisions.

\section{MATERIALS AND METHODS}

Sample collection. Skin samples were collected from whales representing the southern feeding group in Clayoquot Sound, British Columbia, from 1995 to 2006. Individuals of this group appear to move freely between specific feeding sites throughout this southern feeding range from northern California to southeast Alaska in summer (Calambokidis et al. 2002, 2010). Clayoquot Sound on central Vancouver Island is one such site (Darling 1984, Darling et al. 1998). Biopsy samples were collected using a crossbow and modified bolt (e.g. Lambertsen 1987, Palsbøll et al. 1991) or a pneumatic rifle biopsy system (Barrett-Lennard et al. 1996). The samples were collected in association with ongoing photo-identification research (e.g. Darling 1984), and the photo-identification data were used to ensure that individual whales were only represented once within the genetic data set. Moreover, the entire population migrates near this area on its northern and southern migrations. Therefore, samples were only used from whales sampled between 1 July and 15 November, i.e. the time period after which all northward migrants have passed and before which the first migrants start heading south (Darling 1984), to ensure that the sampled individuals actually represented the southern feeding group, as opposed to migratory animals. Tissue samples were stored in a $20 \%$ dimethyl sulfoxide (DMSO) solution (Seutin et al. 1991).

Genetic analysis. Approximately $40 \mathrm{mg}$ from each sample was used for subsequent DNA extraction procedures. The skin was frozen in liquid nitrogen, ground to a fine powder, and transferred to a tube with $500 \mu \mathrm{l}$ of lysis buffer (4 M urea, $0.2 \mathrm{M} \mathrm{NaCl}, 0.5 \%$ $n$-lauroylsarcosine, $10 \mathrm{mM} \mathrm{1,2-cyclohexanediamine-}$ tetraacetic acid, $100 \mathrm{mM}$ Tris- $\mathrm{HCl}, \mathrm{pH}$ 8.0). Samples were rotated in the lysis buffer at room temperature for $\geq 5 \mathrm{~d}$, after which time they were subjected to 3 aliquots of Proteinase $\mathrm{K}$, each at a concentration of $0.5 \mathrm{U} \mathrm{mg}^{-1}$ tissue. The addition of Proteinase K was as follows: after adding the first aliquot, samples were rotated at room temperature overnight; after adding the second aliquot, the samples were placed in a $65^{\circ} \mathrm{C}$ waterbath for $1 \mathrm{~h}$, then transferred to a $37^{\circ} \mathrm{C}$ incubator for $1 \mathrm{~h}$; after adding the third aliquot, the samples were rotated at room temperature overnight. Approximately $250 \mu \mathrm{l}$ of the tissue/lysis buffer solution was subsequently extracted using Qiagen DNeasy Tissue Extraction Kits. DNA quantity was estimated using PicoGreen (Singer et al. 1997). Extracted samples included those previously analyzed by Steeves et al. (2001), which were reextracted and analyzed here, along with the newly collected samples.

A $345 \mathrm{bp}$ portion of the mitochondrial DNA control region was amplified using the primers t-PRO and Primer-2 from Yoshida et al. (2001). PCR cycling conditions consisted of: (1) an initial denaturation step of 5 min at $94^{\circ} \mathrm{C}_{i}(2) 30$ cycles of $94^{\circ} \mathrm{C}$ for $30 \mathrm{~s}, 57^{\circ} \mathrm{C}$ for $1 \mathrm{~min}$, and $72^{\circ} \mathrm{C}$ for $1 \mathrm{~min}$; and (3) a final extension step of $60^{\circ} \mathrm{C}$ for $45 \mathrm{~min}$. Reactions were carried out in $20 \mu \mathrm{l}$ volumes containing $1 \times$ PCR Buffer $(20 \mathrm{mM}$ Tris- $\mathrm{HCl}$ $\mathrm{pH} 8.0,50 \mathrm{mM} \mathrm{KCl}$ ), $0.05 \mathrm{U} \mathrm{\mu l}^{-1}$ Taq polymerase (Invitrogen), $1.5 \mathrm{mM} \mathrm{MgCl} 2,0.2 \mathrm{mM}$ each dNTP (Invitrogen), and $10 \mathrm{ng}$ of DNA. After amplification, primers and unincorporated dNTPs were degraded using EXOSAP-IT (Dugan et al. 2002), and products were sequenced using the DYEnamic dye terminator kit (GE Healthcare). Products were size-separated and visualized on a MegaBACE 1000 (GE Healthcare). Sequences were edited using MEGA 4 (Kumar et al. 2008). Gender was determined for all individuals using the method described by Shaw et al. (2003).

Data analysis. To compare the data from southern feeding group whales to those of the larger population, we compared our mitochondrial sequence data to those reported by LeDuc et al. (2002). Their study reported mitochondrial sequences from 120 ind. representing eastern Pacific gray whales. The majority (>90\%) of the samples were from stranded individuals found throughout their range, from southern California to the Chukotka Peninsula in Russia. The remaining samples were collected from subsistence takes, as biopsies of live whales, and from fisheries bycatch. Fifteen of the samples in LeDuc et al. (2002) were from southern feeding group whales. These were removed from the analyses, leaving 105 samples from the LeDuc et al. (2002) data set to compare with our data set of 40 ind. Because the vast majority of samples from the study by LeDuc et al. (2002) were from dead individuals (either stranded, as bycatch, or hunted), the chance of duplicate samples from the same individual being represented in their data is negligible. Given the num- 
ber and geographic range of the sampled whales in the study by LeDuc et al. (2002), our rationale for choosing these for comparison was that these sequences would be a good representation of the larger population of eastern gray whales.

Sequences were aligned with CLUSTALX (Thompson et al. 1994). Alignments were conducted under a range of gap opening and extension penalties and compared by eye to establish the optimal alignment. The sequences were very similar, and all alignments were the same under the tested conditions. Haplotype and nucleotide diversity $(\pi)$ (Nei 1987) were estimated using Arlequin ver. 3.5.1.2 (Excoffier et al. 2005). Variations between mtDNA sequences were recorded, and identical sequences were grouped into haplotypes. Final haplotype assignments were confirmed with FaBox ver. 1.35 (Villesen 2007). Population differentiation of the mtDNA sequences between the southern feeding group and the larger population was estimated using the analysis of molecular variance approach described by Excoffier et al. (1992) as implemented in the program Arlequin. The significance of the resulting estimates of $F_{\mathrm{ST}}$ and $\Phi_{\mathrm{ST}}$ was tested using 1000 permutations. Relationships among haplotypes were visualized via a median-joining network using the program Network 4.5.1.6 (Fluxus Technology).

To gain insight into the nature of the observed population substructure, we estimated effective population sizes, migration rates, time since divergence, and growth rates for the 2 sample sets using the Isolation with Migration program (IM; Nielsen \& Wakely 2001, Hey \& Nielsen 2004, Hey et al. 2004). However, repeated trials with various parameter options suggested that there was not enough information in our data set to obtain accurate estimates for all of these values (data not shown). Instead, we focused on estimating just the effective population sizes and migration rates using the program MIGRATE (Beerli \& Felsenstein 2001, Beerli 2006). The Bayesian inference approach was implemented, using a transition/transversion ratio of 11.22 and an $\alpha$ estimate of 0.09 for the gamma distribution of mutation rate heterogeneity among sites (both estimated using TREE-PUZZLE, Schmidt et al. 2002). We used the Metropolis-Hastings method of generating posterior distributions. The program was run with uniform prior distributions and 1 long chain. To ensure consistency between runs, MIGRATE was run 5 times with a burn-in of 100000 steps, and a run length of 10000000 steps with data recorded every 500 steps. The likelihood ratio test option of MIGRATE was also used to test the hypothesis that the 2 sample sets have different effective population sizes. For the likelihood ratio test, 10 short chains and 1 long chain were run, with a burn-in of 50000 steps. For the short and long chains, the run length was 10000000 steps with data recorded every 500 steps. Specifically, the hypothesis tested was $\Theta_{\text {southern }}=\Theta_{\text {larger }}$. Theta $(\Theta)$ is a parameter that describes the genetic diversity within a population. The genetic variation existing within a single population is ultimately the result of mutations. The rate at which mutations are observed is a combination of the mutation rate $(\mu)$, which is how often mutations occur, and the effective population size $\left(\mathrm{N}_{\mathrm{e}}\right)$, which represents how many 'opportunities' there are for mutations to occur in each generation. The product of these values represents the probability of a mutation occurring within the population in each generation, and this value is called $\Theta\left(\Theta=N_{e} \mu\right.$ for mitochondrial sequence data). With genetic data, we tend not to know the values of $\mathrm{N}_{\mathrm{e}}$ and $\mu$, but the data available are often the frequency of different DNA sequences and the number of mutations separating them. Thus, it is possible to estimate $\Theta$ from the data, and use that to make inferences of $\mathrm{N}_{\mathrm{e}}$ and $\mu$. Therefore, in this case we can assume that $\mu$ is the same for the southern feeding group and the larger population, and therefore comparisons of $\Theta$ estimates between the 2 groups directly correspond to comparisons of $\mathrm{N}_{\mathrm{e}}$.

\section{RESULTS}

DNA was extracted and mtDNA control regions sequenced from 40 gray whales representing the southern feeding group. Gender was determined for 37 of the 40 sampled whales, and resulted in 15 males and 22 females. This represents a slight female bias, which is contrary to previous studies, which obtained a slight male bias (Steeves et al. 2001). The sequencing protocol resulted in $336 \mathrm{bp}$ of comparable sequence among individuals. Twenty-seven polymorphic sites were identified, which resulted in 18 haplotypes in the southern feeding group whales (Fig. 1). The sequences published in the study by LeDuc et al. (2002) (522 bp) were longer than those obtained here, and therefore all $336 \mathrm{bp}$ from the southern feeding group sequences could be compared to those from the larger population. None of the variable sites or haplotypes identified in the southern feeding group were new; all were also represented by the sequences described by LeDuc et al. (2002) (Fig. 1). However, trimming the sequences of LeDuc et al. (2002) to the comparable 336 bp between the data sets did remove some variable sites that differentiated some of their haplotypes. Specifically, their haplotypes ' $G$ ' and ' $O$ ' were collapsed into 1 sequence (called 'G' in Fig. 1), haplotypes 'L', 'U,' and 'AD' were collapsed into sequence ' $\mathrm{L}$,' and haplotypes 'AC' and 'AG' were collapsed into haplotype 'AC' (Fig. 1).

Although no haplotypes were found only in the southern feeding group samples, the distribution of 


\begin{tabular}{|c|c|c|c|c|c|c|c|c|c|c|c|c|c|c|c|c|c|c|c|c|c|c|c|c|c|c|c|}
\hline Haplotype & $\begin{array}{l}1 \\
9\end{array}$ & $\begin{array}{l}5 \\
3\end{array}$ & $\begin{array}{l}7 \\
3\end{array}$ & $\begin{array}{l}7 \\
4\end{array}$ & $\begin{array}{l}7 \\
5\end{array}$ & & & & $\begin{array}{ll}9 & 9 \\
0 & 1\end{array}$ & $\begin{array}{l}1 \\
0 \\
9\end{array}$ & $\begin{array}{l}1 \\
5 \\
6\end{array}$ & $\begin{array}{ll}1 & 2 \\
7 & 3 \\
8 & 3\end{array}$ & $\begin{array}{ll}2 & 2 \\
3 & 4 \\
3 & 9\end{array}$ & $\begin{array}{l}2 \\
5 \\
0\end{array}$ & $\begin{array}{ll}2 & 2 \\
5 & 5 \\
1 & 6\end{array}$ & $\begin{array}{ll}2 & 2 \\
5 & 6 \\
6 & 9\end{array}$ & $\begin{array}{l}2 \\
7 \\
3\end{array}$ & $\begin{array}{l}2 \\
7 \\
4\end{array}$ & $\begin{array}{l}2 \\
7 \\
5\end{array}$ & $\begin{array}{ll}2 & 2 \\
8 & 9 \\
4 & 2\end{array}$ & $\begin{array}{l}2 \\
9 \\
5\end{array}$ & $\begin{array}{ll}2 & 3 \\
9 & 0 \\
6 & 5\end{array}$ & $\begin{array}{l}3 \\
1 \\
6\end{array}$ & $\begin{array}{l}3 \\
2 \\
4\end{array}$ & $\begin{array}{l}\mathbf{N} \\
\mathbf{F} \\
\mathbf{G}\end{array}$ & $\begin{array}{l}\mathbf{S} \\
\mathbf{F} \\
\mathbf{G}\end{array}$ & $\begin{array}{l}T \\
0 \\
T\end{array}$ \\
\hline A & A & $\mathrm{T}$ & C & $\mathrm{T}$ & $\mathrm{T}$ & $\mathrm{T}$ & T & $C \quad T$ & $\begin{array}{cc}\mathrm{T} & \mathrm{C}\end{array}$ & $G$ & $\mathrm{~T} T$ & $\begin{array}{ll}\mathrm{T} & \mathrm{T}\end{array}$ & $\Gamma \mathrm{G}$ & $\mathrm{T}$ & $A T$ & $\mathrm{~T} T$ & $G$ & $\mathrm{~T}$ & C & $C \mathrm{C}$ & $\mathrm{T}$ & $\begin{array}{ll}\mathrm{T} & \mathrm{T}\end{array}$ & $A$ & A & 12 & 1 & 13 \\
\hline B & . & C & $\mathrm{T}$ & . & C & . & . & T. & $T$ & $A$ & . & . $\mathrm{C}$ & . & C & G. & . C & . & . & & . $T$ & $\mathrm{C}$ & .. & . & $\mathrm{G}$ & 11 & 4 & 15 \\
\hline $\mathrm{C}$ & . & . & . & . & . & . & . & . & $T$ & . & C. & . & . & . & $\mathrm{GC}$ & $\mathrm{CC}$ & . & . & $\mathrm{T}$ &. & . & . & . & . & 9 & 1 & 10 \\
\hline D & . & . & . & . & . & . & . & . & . $T$ & . & . & . & 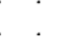 &. & G C & $\mathrm{CC}$ & . & . & $\mathrm{T}$ & . & . & . & . & . & 10 & 1 & 11 \\
\hline E & . & . & . & . & C & . & . & . & $T$ & . & . & . & . & . & G C & C. & . & . & . & . & . & . & . & . & 2 & 0 & 2 \\
\hline G & . & . & . & . & & . & . & . & $T$ & . & . & . & . & . & . C & C. & A & . & . & . & . & . & G & . & 8 & 6 & 14 \\
\hline H & . & . & . & . & . & C & . & . & . . & . & . & . & . & . & G C & $\mathrm{CC}$ & . & . & $\mathrm{T}$ & . $\mathrm{T}$ & . & . & . & . & 0 & 1 & 1 \\
\hline K & . & . & . & . & . & . & . & .0 & $\mathrm{C}$ & . & C & . & . & . & $\mathrm{GC}$ & $\mathrm{CC}$ & . & . & $\mathrm{T}$ & . . & . & . & & . & 4 & 1 & 5 \\
\hline L & . & . & . & . & . & . & . & . . &. & . & . & . & . & . & . $\mathrm{C}$ & C. & A & . & . & . & . & . & $G$ & . & 7 & 2 & 9 \\
\hline$M$ & . & . & . & . & . &. & $C$ & . & . & . & . & . &. & . & . C & C. & A & . & . & . & . & . & $G$ & . & 3 & 7 & 10 \\
\hline $\mathbf{N}$ & . & . & & . & . & . & C & . & . & . & . & . & A & . & . . & . . & . & . & . & . & . & . & $G$ & . & 4 & 4 & 8 \\
\hline $\mathbf{P}$ & G & . & . & . & . & . & . & . & . & . & . & . &. & . & . C & C & . & . & . & . & . & . & . & . & 3 & 0 & 3 \\
\hline Q & . & . & . & . & . & . & . & . & . & . & . & . & . & . & . C & C. & . & . & . & . & . & . & . & . & 1 & 0 & 1 \\
\hline $\mathbf{R}$ & . & . & . & . & . & C & . & . & . & . & . & . & . & . & G C & $\mathrm{CC}$ & . & . & 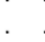 & $\mathrm{T}$ & . &. & . & . & 3 & 1 & 4 \\
\hline S & . & . & . & . & . & C & . & . & $\mathrm{T}$ & . &. & C & . & . & G C & $\mathrm{CC}$ & . & . & $\mathrm{T}$ & $\mathrm{T}$ & 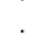 & . & . & . & 1 & 0 & 1 \\
\hline $\mathrm{T}$ & . & . & . & C & . & . & & . & $\mathrm{T}$ & . & . & . & & . & . & . & . & . & .7 & $\mathrm{~T}$ & C & . & & . & 6 & 3 & 9 \\
\hline V & . & . & . & . & . & . & . & . & $\mathrm{T}$ & . & . & . & . & . & . C & C. & . & C & . & . & . & . & . & . & 2 & 0 & 2 \\
\hline$w$ & . & . & . & . & . & . & $C$ & . & . & . & . & . &. &. &. $\mathrm{C}$ & C. &. & . & 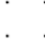 & . &. &. & $\dot{G}$ & 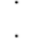 & 1 & 1 & 2 \\
\hline$x$ & . & & & . & . & C & & . & $T$ & . & & . & & . & G & $\mathrm{CC}$ & . & . & $\dot{T}$ & $\mathrm{~T}$ & . & . & . & . & 1 & 0 & 1 \\
\hline$Y$ & . & . & . & . & . & . & . & . 0 & c. & . & . & . & . & . &. $\mathrm{C}$ & C. &. &. & . & . & . &. & . &. & 4 & 1 & 5 \\
\hline $\mathbf{Z}$ & . & . & . & . & . & . & & . . & $\mathrm{T}$ & . & C & . & . & . & $G$ & $\dot{C}$ &. & 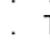 & $\dot{T}$ & . & . &. & &. & 2 & 1 & 3 \\
\hline AA & . & . & . & C & . & . & C & . & $\mathrm{T}$ & . & . & . & $A$ & . & . & . & . & C & & . & . & . & $G$ & . & 1 & 3 & 4 \\
\hline$A B$ & . & . & . & . & . & . & . & . & $\mathrm{T}$ & . & . & . & . & C & G & . C & . & . & $\mathrm{T}$ & . & . & . & . & . & 2 & 0 & 2 \\
\hline$A C$ & . & . & . & . & . & . & & . & $T$ & . & 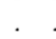 & . & . & C & G & . C & . & & . & . & . & $\mathrm{C} C$ & 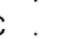 & . & 3 & 2 & 5 \\
\hline $\mathrm{AE}$ & . & . & . & C & . &. & C & . & . & . & . & . & A & . & 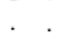 & 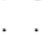 & . & C & & . & . & .. & G & . & 1 & 0 & 1 \\
\hline AF & . & . & . & . & . & . & C & . & & . & C & . & A & . &. & & . & . & $\cdot$ & . & . & . & $G$ & . & 1 & 0 & 1 \\
\hline $\mathrm{AH}$ & & . & . & & C & . & . & . & $\mathrm{T}$ & . & . & . & . & . & G C & $\mathrm{C} \mathrm{C}$ & . & . & $\mathrm{T}$ & . & . & . & . & . & 1 & 0 & 1 \\
\hline $\mathrm{Al}$ & G & . & . & . & . & . & . & . & S. & . & . & . & . & . & . $\mathrm{C}$ & C. & . & . & $\mathrm{T}$ & $\mathrm{T}$ & . & . & . & . & 1 & 0 & 1 \\
\hline AJ & . & . & . & . & . & . & . & . & . & . & . & . & . & . & G C & C. & . & . & . & . & . & . & . & . & 1 & 0 & 1 \\
\hline & & & & & & & & & & & & & & & & & & & & & & otal & & & 105 & 40 & 145 \\
\hline
\end{tabular}

Fig. 1. Eschrichtius robustus. Variable sites characterizing haplotypes from both sample sets of gray whales. NFG, SFG, and TOT (top right) indicate the number of individuals from the northern feeding group (i.e. the larger population), the southern feeding group, and the total number of individuals with each haplotype, respectively

haplotypes was significantly different between the 2 groups, with values of 0.0125 for $F_{\mathrm{ST}}(\mathrm{p}=0.0303)$ and 0.0311 for $\Phi_{\mathrm{ST}}(\mathrm{p}=0.0254)$. The median-joining network shows that although there is some differentiation between the haplotypes from the 2 feeding groups, for the most part the haplotypes from each are scattered throughout the network (Fig. 2). Haplotype diversity and $\pi$ were estimated at 0.928 and 0.0199 , respectively, for the southern feeding group. These values are very similar to estimates obtained for samples representative of the larger population, which were 0.95 and 0.016, respectively (LeDuc et al. 2002).

The results from the MIGRATE analyses are shown in Table 1. Estimates for each value are very similar across iterations, suggesting that the program was run long enough to reach convergence on the estimates. The estimates of $\Theta$ for the southern feeding group and the larger population are clearly different. This observation was confirmed by the likelihood ratio test, which rejected the hypothesis of $\Theta_{\text {southern }}=\Theta_{\text {larger }}(p<0.001)$. The
$95 \%$ confidence intervals for the migration rate estimates are extremely large, making them uninformative. This result is not surprising, however, because the approach implemented by MIGRATE is known to recover precise and accurate estimates of $\Theta$ even in situations where there is not enough information in the data to recover meaningful migration rate estimates (Beerli 2006).

Because the sample of haplotypes found in the southern feeding group represents a subset of the haplotypes found in the larger population (albeit at different frequencies), we conducted further analyses to ensure that our results were not simply due to the effect of sampling. For this assessment, we generated a new set of 40 sequences (representing a simulated southern feeding group data set) by randomly sampling the sequences of LeDuc et al. (2002), using R (R Development Core Team 2009). Thus, this process generated a simulated data set for the southern feeding group under the hypothesis that it represents a random subset of the larger population. This process 


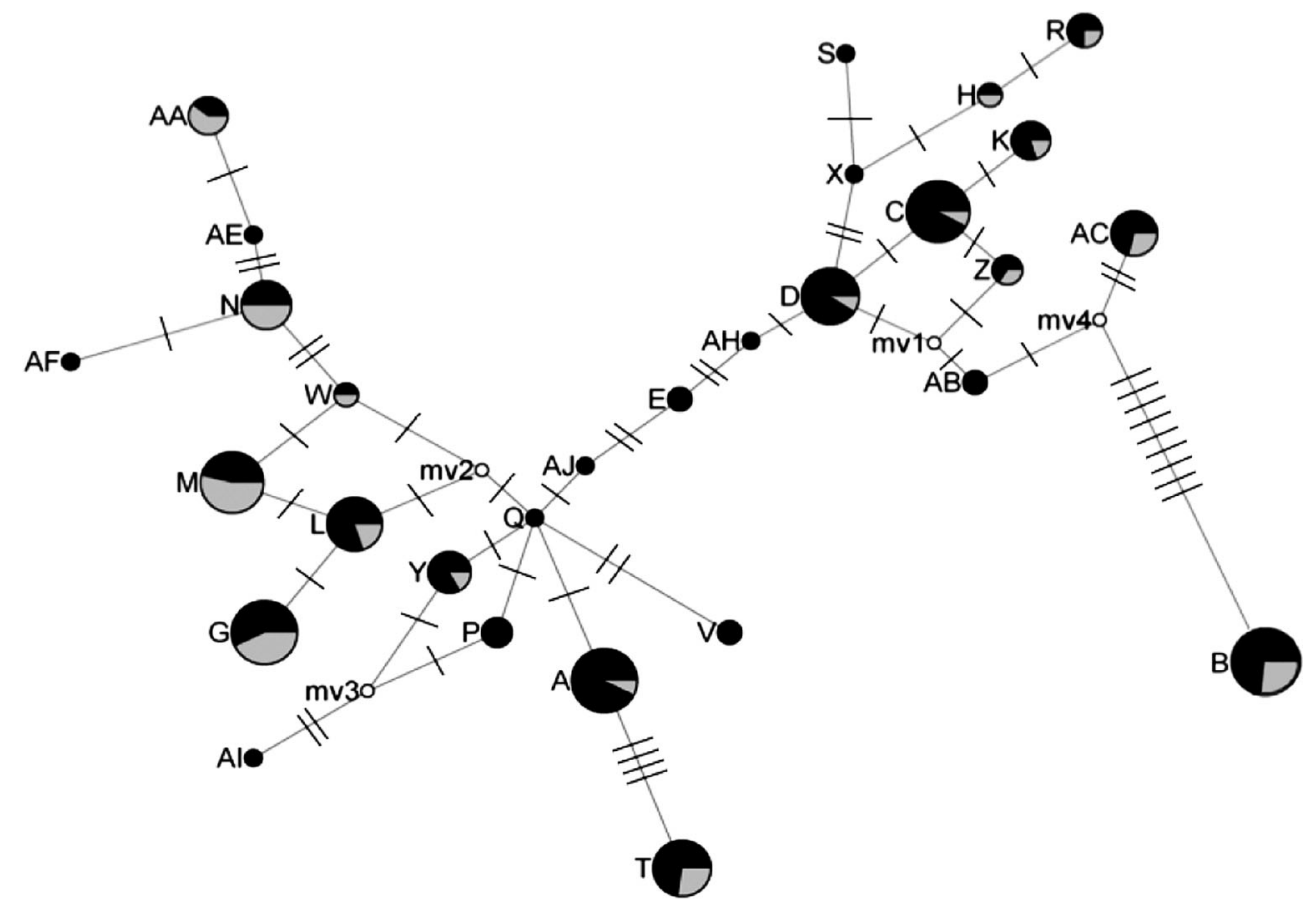

Fig. 2. Eschrichtius robustus. Median-joining network for the gray whale sequences. Transitional mutations are indicated with a line, with the number of lines showing the number of transitional mutations. Lengths of the lines connecting nodes are not proportional to the number of mutations. Sizes of the circles are proportional to the haplotype frequencies in the entire data set. Pie charts indicate the proportion of that haplotype found in the larger population (black) and southern feeding group (gray). 'mv' nodes represent inferred nodes that are missing from the data set

was repeated 10 times, generating 10 simulated data sets containing the data from LeDuc et al. (2002), as well as the simulated data for the southern feeding group. Analyses of $F_{\mathrm{ST}}$ and $\Phi_{\mathrm{ST}}$ were conducted for

Table 1. Eschrichtius robustus. Results from the MIGRATE analysis. Included is the estimated mean for each parameter, as well as the $95 \%$ credibility intervals in parentheses (both obtained using the Bayesian approach in MIGRATE). $M$ is the immigration rate $m$ divided by the mutation rate $\mu$. For mitochondrial DNA data, the number of immigrants per generation can be calculated by multiplying $M$ by $\Theta$. Included are the estimates for each of the 5 iterations of the program, as well as the average across all 5 iterations. Southern and larger indicate the southern feeding group of the eastern North Pacific gray whale population, and larger population, respectively

\begin{tabular}{|lcccc|}
\hline \multirow{2}{*}{ Iteration } & $\Theta_{\text {larger }}$ & $\Theta_{\text {southern }}$ & $M_{\text {southern-larger }}$ & $M_{\text {northern-southern }}$ \\
\hline 1 & 0.0430 & 0.0206 & 522 & 572 \\
& $(0.0220-0.0690)$ & $(0.00550-0.0380)$ & $(205-860)$ & $(250-920)$ \\
2 & 0.0462 & 0.0199 & 516 & 565 \\
& $(0.0235-0.0735)$ & $(0.00550-0.0385)$ & $(190-865)$ & $(245-960)$ \\
3 & 0.0437 & 0.0208 & 523 & 562 \\
& $(0.0205-0.0730)$ & $(0.00650-0.0385)$ & $(195-870)$ & $(210-920)$ \\
4 & 0.0421 & 0.0212 & 515 & 572 \\
& $(0.0165-0.0715)$ & $(0.00650-0.0425)$ & $(190-865)$ & $(240-950)$ \\
5 & 0.0430 & 0.0220 & 480 & 526 \\
& $(0.0200-0.0710)$ & $(0.00650-0.0445)$ & $(175-810)$ & $(195-875)$ \\
Avg & 0.0436 & 0.0209 & 511 & 559 \\
& $(0.0205-0.0716)$ & $(0.00610-0.0404)$ & $(191-854)$ & $(228-925)$ \\
\hline
\end{tabular}

each simulated data set using Arlequin, as were likelihood ratio tests for testing the hypothesis of $\Theta_{\text {southern }}=$ $\Theta_{\text {larger }}$ using MIGRATE, under the same conditions as were used for the original data.

None of the simulated data sets showed significant signs of structuring based on $F_{\mathrm{ST}}$ or $\Phi_{\mathrm{ST}}$, and none showed significant differences in estimates of $\Theta$ (Table 2). Thus, the significant differentiation found for the real data set, based on all 3 of these analyses, suggests that the observed differentiation is indeed real, and not just an artifact of sampling.

\section{DISCUSSION}

The conservation and/or management of wildlife populations requires knowledge of how individuals are subdivided into separate entities that have relatively independent demographic processes, which are often referred to as 'management units' (MU). Such information is required to identify how each unit, and the popu- 
Table 2. Eschrichtius robustus. Results from simulation tests under the hypothesis that the southern feeding group represents a random sample of the data set from LeDuc et al. (2002). Included are the $F_{\mathrm{ST}}$ and $\Phi_{\mathrm{ST}}$ estimates, and associated p-values (in parentheses), from Arlequin, as well as p-values from likelihood ratio tests conducted in MIGRATE testing the hypothesis of $\Theta_{\text {southern }}=\Theta_{\text {larger }}$, where southern is the southern feeding group of the eastern North Pacific gray whale population, and larger is the larger population (not including the southern feeding group)

\begin{tabular}{|c|c|c|c|}
\hline \multicolumn{2}{|c|}{ Iteration } & $\Phi_{\mathrm{ST}}$ & $\begin{array}{c}\text { southern } \\
\mathrm{p}\end{array}$ \\
\hline 1 & $-0.01136(0.9991)$ & $-0.01489(1.000)$ & 0.9882 \\
\hline 2 & $-0.00180(0.5699)$ & $-0.00266(0.5122)$ & 0.7236 \\
\hline 3 & 0.00019 (0.4018) & $-0.00673(0.7224)$ & 0.1658 \\
\hline 4 & $-0.00980(0.9863)$ & $-0.01235(0.9717)$ & 0.9421 \\
\hline 5 & $-0.01047(1.000)$ & $-0.01156(0.9609)$ & 0.1167 \\
\hline 6 & $-0.00578(0.8651)$ & $-0.00873(0.8358)$ & 0.9632 \\
\hline 7 & $-0.00445(0.7859)$ & $-0.01000(0.9042)$ & 0.9805 \\
\hline 8 & $0.00146(0.3744)$ & $-0.00448(0.6090)$ & 0.1023 \\
\hline 9 & $-0.00419(0.7468)$ & $-0.00889(0.8436)$ & 0.7233 \\
\hline 10 & $-0.00531(0.82796)$ & $0.00425(0.2678)$ & 0.2074 \\
\hline
\end{tabular}

lation as a whole, will respond to exploitation and/or unintentional impacts. Moritz (1994) was the first to provide a working definition of MUs in a population genetics context, and defined them as

...populations with significant divergence of allele frequencies at nuclear or mitochondrial loci, regardless of the phylogenetic distinctiveness of the alleles. (p. 374)

While this definition has been widely applied in population genetics studies, it has recently been argued that MUs should be defined based on criteria demonstrating demographic isolation rather than simply rejecting the hypothesis of panmixia (Waples \& Gaggiotti 2006, Palsbøll et al. 2007, Waples et al. 2008). This idea makes intuitive sense, because the true question for management is whether the units will respond differently to the pressures of concern (e.g. exploitation and/or unintentional mortality). However, there is a disconnect between inferring demographic independence and genetic estimates of differentiation because populations can be demographically independent even when long-term migration rates are high enough to result in relative genetic homogeneity (Waples \& Gaggiotti 2006, Waples et al. 2008).

The data presented here show that the southern feeding group of gray whales represents a distinct MU under both of these criteria. The analysis showing statistically significant differentiation of mitochondrial haplotypes demonstrates qualification as an MU under the criteria of Moritz (1994). Moreover, the analysis showing that the effective sizes of both groups are different $\left(\Theta_{\text {southern }} \neq \Theta_{\text {larger }}\right)$ shows that the maternal lineages of the southern feeding group represent a distinct seasonal subpopulation. Indeed, if they were not an independent unit but instead just represent different samples from the same mitochondrial 'population,' then estimates of $\Theta$ from the 2 data sets should converge on the same value. Thus, the southern feeding group qualifies as a separate MU under the criterion of Palsbøll et al. (2007). Combined, these data show that the southern feeding group requires separate management consideration with regards to resuming whaling.

Hastings (1993) showed that populations behave in a demographically independent manner when migration rates are less than $\sim 10 \%$. We have intentionally not converted $\Theta$ estimates to $\mathrm{N}_{\mathrm{e}}$ estimates because this requires knowledge of the substitution rate $(\mu)$. Estimates of $\mu$ for the control region of baleen whale mtDNA vary by over an order of magnitude (e.g. Rooney et al. 2001). Moreover, $\mu$, whatever its true value is, is undoubtedly the same for the southern feeding group and the larger population, and therefore comparing estimates of $\Theta$ is an appropriate and less controversial method for comparing $\mathrm{N}_{\mathrm{e}}$. Regardless, if we apply the $\mu$ estimate of $1.0 \times 10^{-10}$ mutations site ${ }^{-1} \mathrm{yr}^{-1}$, estimated by Alter \& Palumbi (2009) for North Pacific gray whales, the resulting estimates of migration rates are $<<1 \%$. In this case, we are not dealing with migration rates between reproductive populations per se, but rather exchange rates between maternally based feeding groups. As with the haplotype frequency data, this result shows that the southern feeding group represents a distinct seasonal subpopulation.

Estimates of $\Theta$ represent long-term averages over the lifetime of the population; therefore, these genetic analyses provide information on an evolutionary time scale, whereas wildlife managers are generally more interested in the current state of a population (e.g. at the ecological time scale; Waples et al. 2008). To address this disconnect, we reiterate that photo-identification data of contemporary individuals also results in the same conclusion that the southern feeding group represents a distinct seasonal subpopulation based on maternally directed site fidelity. Photo-identification data show that the majority of whales sighted in the southern feeding areas are re-sighted there in subsequent years (Darling 1984, Calambokidis et al. 2002), and that the majority of calves first sighted in the southern feeding area with their mothers are resighted there as juveniles and adults (Calambokidis et al. 2010). Therefore, the combination of photo-identification and genetic data suggests distinct subdivision of the southern feeding group at both the evolutionary and contemporary (or ecological) time scales.

We reiterate that the southern feeding group likely mates with the rest of the population in the winter breeding grounds, and that the structuring we see is the result of maternally directed site fidelity to different feeding grounds. We used mtDNA (rather than 
nuclear markers) to test this hypothesis specifically for this reason, because such a pattern would be reflected in mtDNA and not nuclear DNA. This type of population substructure is common in whales (e.g. Hoelzel 1998), and has proven important for management. The rationale is that, because of this site fidelity, knowledge of specific feeding areas is only present within certain matrilines. Therefore, if whales are extirpated from a specific feeding ground, they will not be 'replaced' (or the area will not be re-populated) by others from the larger population because knowledge of that feeding area has been lost. Indeed, such localized extinctions and lack of subsequent re-population of areas (despite an increasing overall population size) is widely documented in whales (e.g. Northridge 2008). Thus, the combined genetic and photo-identification data showing that the southern feeding group represents a distinct maternally based seasonal subpopulation indicate that these whales require separate management consideration from the larger population.

Previous studies have suggested that the haplotype diversity in the southern feeding group is too high to have resulted from strict maternally directed site fidelity beginning with a few founders after the cessation of commercial whaling within the past century (Ramakrishnan et al. 2001). Under the hypothesis that this group was founded after the cessation of whaling, only a few closely related haplotypes should be represented within the southern feeding group, as opposed to the pattern seen in Fig. 2. In addition, the hypothesis of a founding event within the past century is not consistent with the known sighting information. Indeed, gray whales have been seen in the southern feeding grounds throughout their history, including in times of lowest abundance (Swartz et al. 2006, and references therein). Moreover, if a few individuals recently founded the southern feeding group, then the estimate of $\Theta_{\text {southern }}$ should be substantially smaller, as effective population size estimates are heavily influenced by bottlenecks.

Instead, what the sighting and genetic data suggest is that the southern feeding group of gray whales predates whaling. Under this hypothesis, the haplotype diversity is expected to be high, because those lineages that survived whaling would be a random sample from a much larger population. Substantial gaps would also be expected between existing haplotypes resulting from the removal of haplotypes by whaling. This pattern is exactly what is seen in Fig. 2. The similarity of haplotypes, and the degree of haplotype sharing between the southern feeding group and the larger population, both suggest some degree of migration between the 2 groups. However, although reliable estimates of migration rates could not be obtained here, the data clearly show that the rate of migration is low enough for the 2 groups to represent independent demographic entities. The southern feeding group therefore qualifies as a separate $\mathrm{MU}$, and requires separate management consideration.

A larger sample set, and the analysis of more molecular markers (particularly nuclear markers), is obviously desirable for addressing topics such as this one. Moreover, it is possible that further structuring within each of these identified groups exists, but is as yet undetected. However, given the clarity of the results obtained and the implications that they have for the management of these whales, it seemed important to publish these data as soon as possible so that they could be available for informing management decisions. We are currently collecting more samples and collaborating with other scientists to increase the number and geographical representation of our sample set. Protocols for analyzing nuclear loci are also being developed. Combined, these efforts will allow for larger-scale analyses of this issue in the near future.

Acknowledgements. Funding for this work came from the Natural Sciences and Engineering Research Council of Canada (NSERC), a Canadian Research Chair grant to B.N.W., and the Pacific Wildlife Foundation through donations from Remote Passages and Jamie's Whaling Station, and a grant from Clayoquot Biosphere Trust in Tofino, BC. We acknowledge the earlier work on this subject by T. Steeves and the transfer of her samples to this data set. We also thank A. Lang for help identifying which southern feeding group samples were duplicated in the LeDuc et al. (2002) data set. We thank the members of the Aboriginal Whaling Management Procedure (AWMP) scientific committee of the International Whaling Commission (IWC), N. Rose, and 3 anonymous reviewers for comments and discussions that improved this manuscript.

\section{LITERATURE CITED}

Alter SE, Palumbi S (2009) Comparing evolutionary patterns and variability in the mitochondrial control region and cytochrome $\mathrm{b}$ in three species of baleen whales. J Mol Evol 68:97-111

Alter SE, Rynes E, Palumbi SR (2007) DNA evidence for historic population size and past ecosystem impacts of gray whales. Proc Natl Acad Sci USA 104:15162-15167

Baker CS, Palumbi SR, Lambertsen RH, Weinrich MT, Calambokidis J, O'Brien SJ (1990) Influence of seasonal migration on geographic distribution of mitochondrial DNA haplotypes in humpback whales. Nature 344:238-240

Barrett-Lennard LG, Smith TG, Ellis GM (1996) A cetacean biopsy system using lightweight pneumatic darts, and its effect of the behavior of killer whales. Mar Mamm Sci 12: $14-27$

> Beerli P (2006) Comparison of Bayesian and maximumlikelihood inference of population genetic parameters. Bioinformatics 22:341-345

> Beerli P, Felsenstein J (2001) Maximum likelihood estimation of a migration matrix and effective population sizes in $n$ subpopulations by using a coalescent approach. Proc Natl Acad Sci USA 98:4563-4568 
Butterworth DS, Korrûbel JL, Punt AE (2002) What is needed to make a simple density-dependent response population model consistent with data for the eastern gray whales? J Cetacean Res Manag 4:63-76

Calambokidis J, Darling JD, Deecke V, Gearin P and others (2002) Abundance, range and movements of a feeding aggregation of gray whales (Eschrichtius robustus) from California to southeastern Alaska in 1998. J Cetacean Res Manag 4:267-276

Calambokidis J, Laake JL, Klimek A (2010) Abundance and population structure of seasonal gray whales in the Pacific Northwest, 1998-2008. Paper SC/62/BRG32 presented to the IWC Scientific Committee, Agadir, May 2010

$>$ Caughley G (1966) Mortality patterns in mammals. Ecology 47:906-918

Darling JD (1984) Gray whales off Vancouver Island, British Columbia. In: Jones ML, Swartz SL, Leatherwood S (eds) The gray whale, Eschrichtius robustus. Academic Press, Orlando, FL, p 267-287

Darling JD, Keogh KE, Steeves TM (1998) Gray whale (Eschrichtius robustus) habitat utilization and prey species off Vancouver Island, B.C. Mar Mamm Sci 14:692-720

> Daugherty CH, Cree A, Hay JM, Thompson MB (1990) Neglected taxonomy and continuing extinctions of tuatara (Sphenodon). Nature 347:177-179

Dugan KA, Lawrence HS, Hares DR, Fisher CL, Budowle B (2002) An improved method for post-PCR purification for mtDNA sequence analysis. J Forensic Sci 47:811-818

Excoffier L, Smouse P, Quattro J (1992) Analysis of molecular variance inferred from metric distances among DNA haplotypes: application to human mitochondrial restriction data. Genetics 131:479-491

Excoffier L, Laval G, Schneider S (2005) Arlequin ver.3.0: an integrated software package for population genetics data analysis. Evol Bioinf Online 1:47-50

Findley LT, Vidal O (2002) Gray whale (Eschrichtius robustus) at calving grounds in the Gulf of California, Mexico. J Cetacean Res Manag 4:27-40

Frankham R, Ballou JD, Briscoe DA (2002) Introduction to conservation genetics. Cambridge University Press, Cambridge

Hastings A (1993) Complex interactions between dispersal and dynamics: lessons from coupled logistic equations. Ecology 74:1362-1372

Hatler DF, Darling JD (1974) Recent observations of the gray whale in British Columbia. Can Field Nat 88:449-459

Henderson DA (1984) Nineteenth century gray whaling: grounds, catches and kills, practices and depletion of the whale population. In: Jones MJ, Swartz SL, Leatherwood $\mathrm{S}$ (eds) The gray whale: Eschrichtius robustus. Academic Press, Orlando, FL, p 159-186

> Hey J, Nielsen R (2004) Multilocus methods for estimating population sizes, migration rates and divergence time, with applications to the divergence of Drosophila pseudoobscura and D. persimilis. Genetics 167:747-760

Hey J, Won YJ, Sivasundar A, Nielsen R, Markert JA (2004) Using nuclear haplotypes with microsatellites to study gene flow between recently separated cichlid species. Mol Ecol 13:909-919

Hoelzel AR (1998) Genetic structure of cetacean populations in sympatry, parapatry, and mixed assemblages: implications for conservation policy. J Hered 89:451-458

Kumar S, Nei M, Dudley J, Tamura K (2008) MEGA: a biologist-centric software for evolutionary analysis of DNA and protein sequences. Brief Bioinf 9:299-306

Lambertsen RH (1987) A biopsy system for large whales and its use for cytogenetics. J Mammal 68:443-445
LeDuc RG, Weller DW, Hyde J, Burdin AM and others (2002) Genetic differences between western and eastern gray whales (Eschrichtius robustus). J Cetacean Res Manag 4: 1-5

Malik S, Brown MW, Kraus SD, Knowlton AR, Hamilton PK, White BN (1999) Assessment of mitochondrial DNA structuring and nursery use in the North Atlantic right whale (Eubalaena glacialis). Can J Zool 77:1217-1222

Moore SE, Ljungblad DK (1984) Gray whales in the Beaufort, Chukchi, and Bering Seas: distribution and sound production. In: Jones ML, Swartz SL, Leatherwood S (eds) The gray whale, Eschrichtius robustus. Academic Press, Orlando, FL, p 543-559

Moore SE, Urban RJ, Perryman WL, Gulland F and others (2001) Are gray whales hitting 'K' hard? Mar Mamm Sci 17:954-958

Moritz C (1994) Defining 'evolutionary significant units' for conservation. Trends Ecol Evol 9:373-375

Nei M (1987) Molecular evolutionary genetics. Columbia University Press, New York, NY

Nielsen R, Wakely J (2001) Distinguishing migration from isolation: a Markov chain Monte Carlo approach. Genetics 158:885-896

Northridge S (2008) Bycatch. In: Perrin WF, Würsig B, Thewissen JGM (eds) Encyclopedia of marine mammals, 2nd edn. Academic Press, Orlando, FL, p 167-169

O'Leary BL (1984) Aboriginal whaling from the Aleutian Islands to Washington State. In: Jones MJ, Swartz SL, Leatherwood S (eds) The gray whale: Eschrichtius robustus. Academic Press, Orlando, FL, p 79-102

Palsbøll PJ, Larsen F, Hansen ES (1991) Sampling of skin biopsies from free-ranging large cetaceans in west Greenland: development of new biopsy tips and bolt designs. Rep Int Whaling Comm Spec Issue 13:71-79

Palsbøll PJ, Bérubé M, Allendorf FW (2007) Identification of management units using population genetic data. Trends Ecol Evol 22:11-16

Pike GC (1962) Migration and feeding of the gray whale (Eschrichtius gibbosus). J Fish Res Board Can 19:815-838

R Development Core Team (2009) R: a language and environment for statistical computing. R Foundation for Statistical Computing, Vienna. Available at www.R-project.org

Ramakrishnan U, LeDuc R, Darling J, Taylor BL and others (2001) Are the southern feeding group of eastern Pacific gray whales a maternal genetic isolate? Paper SC/53/SD8 presented to the IWC Scientific Committee, July 2001

Reeves RR (1984) Modern commercial pelagic whaling for gray whales. In: Jones MJ, Swartz SL, Leatherwood S (eds) The gray whale: Eschrichtius robustus. Academic Press, Orlando, FL, p 187-200

Reilly SB (1992) Population biology and status of eastern Pacific gray whales: recent developments. In: McCullough DR, Barrett RH (eds) Wildlife 2001: populations. Elsevier Applied Science Publishers, London, p 1062-1074

> Rooney AP, Honeycutt RL, Derr JN (2001) Historical population size change of bowhead whales inferred from DNA sequence polymorphism data. Evolution 55:1678-1685

Rugh DJ, Hobbs RC, Lerczak JA, Breiwick JM (2005) Estimates of abundance of the eastern North Pacific stock of gray whales (Eschrichtius robustus) 1997-2002. J Cetacean Res Manag 7:1-12

Russell D (2004) The eye of the whale: epic passage from Baja to Siberia. Island Press, Chicago, IL

Schmidt HA, Strimmer K, Vingron M, von Haeseler A (2002) TREE-PUZZLE: maximum likelihood phylogenetic analysis using quartets and parallel computing. Bioinformatics 18:502-504 
Seutin G, White BN, Boag PT (1991) Preservation of avian blood and tissue samples for DNA analysis. Can J Zool 69:82-90

Shaw CN, Wilson PJ, White BN (2003) A reliable molecular method of gender determination for mammals. J Mammal 84:123-128

Shelden KEW, Laake JL (2002) Comparison of the offshore distribution of southbound migratory gray whales from aerial survey data collected off Granite Canyon, California, 1979-1996. J Cetacean Res Manag 4:53-56

Singer VL, Jones LJ, Sue ST, Haugland RP (1997) Characterization of PicoGreen reagent and development of a fluorescent-based solution assay for double-stranded DNA quantitation. Anal Biochem 249:228-238

Steeves TE, Darling JD, Rosel PE, Schaeff CM, Fleischer RC (2001) Preliminary analysis of mitochondrial DNA variation in a southern feeding group of eastern North Pacific gray whales. Conserv Genet 2:379-384

Swartz SL (1986) Gray whale migratory, social and breeding behavior. Rep Int Whaling Comm Spec Issue 8:207-229

Swartz SL, Taylor BL, Rugh DJ (2006) Gray whale Eschrichtius robustus population and stock identity. Mammal Rev 36:66-84

Taylor BL (1997) Defining 'population' to meet management objectives for marine mammals. In: Dizon AE, Chivers SJ,

Editorial responsibility: Helene Marsh,

Townsville, Queensland, Australia
Perrin WF (eds) Molecular genetics of marine mammals. The Society for Marine Mammalogy, Lawrence, KS, p 49-65

Thompson JD, Higgins DG, Gibson TJ (1994) CLUSTAL W: improving the sensitivity of progressive multiple sequence alignment through sequence weighting, position-specific gap penalties and weight matrix choice. Nucleic Acids Res 22:4673-4680

Villesen P (2007) FaBox: an online toolbox for FASTA sequences. Mol Ecol Notes 7:965-968

Wade PR (2002) A Bayesian stock assessment of the eastern Pacific gray whale using abundance and harvest data from 1967 to 1996. J Cetacean Res Manag 4:85-98

Waples RS, Gaggiotti O (2006) What is a population? An empirical evaluation of some genetic methods for identifying the number of gene pools and their degree of connectivity. Mol Ecol 15:1419-1439

Waples RS, Punt AE, Cope JM (2008) Integrating genetic data into management of marine resources: How can we do it better? Fish Fish 9:423-449

Yoshida H, Yoshioka M, Shirakihara M, Chow S (2001) Population structure of finless porpoises (Neophocaena phocaenoides) in coastal waters of Japan based on mitochondrial DNA sequences. J Mammal 82:123-130

Submitted: April 6, 2010; Accepted: February 1, 2011

Proofs received from author(s): April 3, 2011 